\title{
Multivariate Data Analysis of Thermally Treated Sicilian Extravirgin Olive Oils. Coupling of Electronic Nose, Gas Chromatography-mass Spec- trometry and Rheology Techniques
}

\author{
Margherita Amenta ${ }^{1}$, Maria Eugenia Monge ${ }^{2}$, Leonardo Lizarraga $^{2}$, Daniela Giacomazza ${ }^{1}$, Valeria \\ Guarrasi $^{1}$, Pier Luigi San Biagio ${ }^{1, *}$ and Donatella Bulone ${ }^{1}$ \\ ${ }^{1}$ Istituto di BioFisica-U.O.S. di Palermo, Consiglio Nazionale delle Ricerche. Via U. La Malfa 153, I-90146, Palermo, \\ Italia \\ ${ }^{2}$ INQUIMAE and Departamento de Química Inorgánica, Analitica y Química Física, Facultad de Ciencias Exactas y \\ Naturales, UBA, Ciudad Universitaria, Pabellón II, C1428EHA, Buenos Aires, Argentina
}

\begin{abstract}
In this work we describe the chemical and physical changes of Sicilian extra virgin olive oil (EVOO) heated at $90^{\circ}$ in a conventional oven for one month. The effects of the thermal treatment along days on volatile compounds and viscosity were monitored using electronic nose, gas chromatography and rheology. Data obtained by these techniques were combined in order to create a data matrix for the analysis, and the unsupervised method Principal Component Analysis (PCA) was used. A synergistic effect was obtained by combining all data, thus allowing discriminating oil samples according to their oxidative status.
\end{abstract}

Keywords: Extra virgin olive oil, thermal oxidation, viscosity, electronic nose, HS-SPME, GC-MS, PCA.

\section{INTRODUCTION}

The extra virgin olive oil (EVOO) compared to other edible vegetable oils has excellent sensorial and nutritional properties, thanks to a group of phenolic compounds, polyphenols and tocopherols, that contribute to its taste (bitter and pungency) $[1,2]$, and have beneficial effects on human health (anticancer, antioxidant and anti-inflammatory properties) [3-5]. Moreover, the EVOO presents a triacylglycerol composition very low in polyunsaturated fatty acids. These chemical characteristics prolong the EVOO shelf life by imparting a high oxidative stability that preserves its intrinsic qualities [6].

The good properties of EVOO decrease with time due to the presence of many factors (air, heat, light and metals) leading to oxidation [7]. One of the most applied methods for studying this process is to follow the chemical-physical properties changes of EVOO caused by the exposure at high temperatures. Indeed, heating effects have been studied by using a large variety of experimental techniques and protocols [8-10].

Particular attention has been paid to the oxidation of olive oil with the aim of assessing benefits of its use with respect to that of other vegetable oils. One major concern is the healthiness of the olive oil for deep-frying purpose [11$15]$, as related to a minor polymerization extent and lower

\footnotetext{
*Address correspondence to this author at the Istituto di BioFisica-U.O.S. di Palermo, Consiglio Nazionale delle Ricerche. Via U. La Malfa 153, I90146, Palermo, Italia; Tel.: +390916809311; Fax: +390916887692;

E-mail: pierluigi.sanbiagio@pa.ibf.cnr.it
}

content of polar compounds after repeated frying cycles [16]. Another topic of interest regards the higher stability of the olive oil toward oxidation, due to a lower amount of unsaturated fatty acids $[11,17]$ and a higher content of antioxidant agents such as biophenols, alfa-tocopherol [18-21]. In this case, a soft thermal treatment is used to conveniently speed up the oxidation process.

The quantification of the oxidation extent is usually accomplished by using different indicators since the process complexity and its dependence on many parameters make no feasible the use of a unique method for representing all related chemical physical changes $[22,23]$. In fact, at the beginning of oxidation, molecular oxygen reacts with double bonds of unsaturated fatty acids to produce hydroperoxides, whose amount is in general used for monitoring the initial oxidation stage together with measurements of oxygen consumption and formation of conjugated dienes and trienes [22]. Hydroperoxides rapidly decompose in secondary oxidation products such as hydrocarbons, alcohols, aldehydes, and ketones $[18,24,25]$ whose increase can be determined by GC-MS. Differently from other vegetable oils, the extra virgin olive oil does not undergo chemical treatments during its processing, thus retaining some volatile compounds that contribute to give its unique and characteristic flavor [26]. The progressive advancement of oxidation results in the development of unpleasant volatile compounds, which are responsible for the so named "off-flavors" [27]. The detection of this type of defect in extra virgin olive oil has been officially prescribed [28] to be carried out through sensory panel test, but many efforts have been devoted to find meas- 
Table 1. MOS Sensor Array Configuration of the EOS835(Sacmi Imola, Italy)

\begin{tabular}{|c|c|c|c|c|}
\hline Id & Code & Sensing Layer & Catalyst & Operating Temperature \\
\hline \hline 1 & $\mathrm{CJ} 1316$ & $\mathrm{SnO}_{2}$ & $\mathrm{SiO}_{2}$ & $450^{\circ} \mathrm{C}$ \\
\hline 2 & $\mathrm{SB} 0225$ & $\mathrm{SnO}_{2}$ & $\mathrm{Ag}$ & $400{ }^{\circ} \mathrm{C}$ \\
\hline 3 & $\mathrm{SD} 0515$ & $\mathrm{SnO}_{2}$ & $\mathrm{Mo}$ & $400{ }^{\circ} \mathrm{C}$ \\
\hline 4 & $\mathrm{SH} 0612$ & $\mathrm{WO}_{3}$ & - & $375^{\circ} \mathrm{C}$ \\
\hline 5 & $\mathrm{SJ} 0717$ & $\mathrm{SnO}_{2}$ & - & $450^{\circ} \mathrm{C}$ \\
\hline 6 & $\mathrm{WHT} 19$ & $\mathrm{WO}_{3}$ & - & $400^{\circ} \mathrm{C}$ \\
\hline
\end{tabular}

urable quantities that could be correlated to human sensorial responses [26, 29-31].

When advanced oxidation stages are reached in samples kept at high temperature, a viscosity increase is observed, as related to the increase of the amount of polar compounds $[13,15,32]$ and the beginning of a polymerization process [33] due to the H-bound formation between polar compounds [34]. No irreversible change in viscosity is instead observed in oil samples during a heating and cooling run from 10 to $80{ }^{\circ} \mathrm{C}$ temperature range [32].

As each of the experimental methods and techniques used is able to get insights on some peculiar aspect or stage of oxidation, the applying of statistical methods to the analysis of different types of data could be a convenient tool for discriminating the oxidative stage. In this study, different Sicilian extra virgin olive oil samples were thermally oxidized by heating at $90{ }^{\circ} \mathrm{C}$. The exposure time was chosen long enough to observe oxidative phenomena similar to that observed at higher temperature, as previous reported by Navarra et al. [34].We applied a joint analysis of data obtained from three different experimental techniques: electronic nose, gas chromatography and rheology. The question that we wanted to answer was if these three techniques together would improve the determination of the oxidative state of extra virgin olive oils through the use of multivariate methods generally applied for discriminating between different oils [24, 35, 36] and determining which parameters are the most relevant in defining the oxidative state $[37,38]$. Furthermore, we tested the potential use of this methodology for improving the discrimination between different oils according to their response to the oxidative stress.

\section{MATERIALS AND METHODS}

\subsection{Materials}

Olive oil samples from different regions of Sicily, were supplied by Sicilian oil producers in the frame of a European project and subjected to the lawful analyses certifying their belongings to extra virgin oil category [39]. Samples will be referred as EVOO 1 (monocultivar 'Giarraffa'), EVOO 2 (blend to cultivar 'Nocellara del Belice' and 'Biancolilla'), EVOO 3 (monocultivar 'Nocellara del Belice') and EVOO 4 (monocultivar 'Biancolilla'). Before the experiments, the oil samples were stored in the dark at $10{ }^{\circ} \mathrm{C}$.

\subsection{Sample Conditioning}

Two grams of each oil sample were placed into a $10 \mathrm{ml}$ vial sealed with a pierceable silicone septum. One group of vials was used for the headspace analysis with the electronic nose, and the other group was used either for the headspacesolid-phase-micro-extraction gas chromatography analysis and viscosity measurement. Several aliquots of each oil sample were placed in a laboratory oven at $90{ }^{\circ} \mathrm{C}$ and withdrawn in triplicate after a time interval of 7, 14 and 28 days. They will be referred in the text as 7D, 14D and 28D respectively, whereas samples of fresh oil without thermal treatment will be referred as NT. Measurements with the different techniques were all performed at $40^{\circ} \mathrm{C}$.

\subsection{Electronic Nose}

The device used in this work was the Electronic Olfactory SystemEOS ${ }^{835}$ manufactured by the Italian company SACMI Imola s.c.a.r.l. This device has already been described by Falasconi et al. (2005) [40]. It comprised an array of 6 Metal Oxide Semiconductor (MOS) gas sensors, which were incorporated into a sample chamber (Table I). The sensors' electrical resistance diminishes in presence of the volatile compounds. Each sensor has a different response because they are unspecific for the volatile compounds.

During the measurement each sensor was maintained at a temperature range of $350-450^{\circ} \mathrm{C}$. Data acquisition was made with the software EOS.

After of the introduction into the tray each sample was placed into a closed oven that was incorporated in the electronic nose instrument. Samples were conditioned in the oven at $40{ }^{\circ} \mathrm{C}$ for 10 minutes. After that, $4 \mathrm{ml}$ were drawn from the headspace by using an autosampler (model HT200H) coupled with a syringe, and introduced into the gas sensors chamber. The analysis time of the samples was 1 minute. Three vials for each sample were measured.

Before and after the inclusion of the volatile compounds into the gas sensor chamber, a flow $(100 \mathrm{cc})$ of chromatographic air was used to clean the sensors and restore the base line. We used as a sensor feature the value $\triangle \mathrm{R}_{i}=\mathrm{R}_{i}{ }^{0}$ $\mathrm{R}_{i}$, where $\mathrm{R}_{i}^{0}$ is the resistance of sensor $i$, in presence of chromatographic air (base line) and $\mathrm{R}_{i}$ is the minimum resistance in presence of the volatile sample. A set of six features $\left\{\triangle R_{1}, \ldots, \triangle R_{6}\right\}$ was obtained in each measurement. 
The whole set of sensors' features is referred to a fingerprint. Results can be conveniently represented as a radar plot in which each vertex corresponds to the signal of each sensor. Differences and similarities between different samples may be visually identified by comparing their radar plots.

\subsection{Gas Chromatography-Mass Spectrometry}

Olive oils samples were analyzed with SPME and gas chromatography combined with mass spectrometry (GC/MS) in order to identify and quantify their main components.

Volatile compounds in the headspace were extracted and concentrated by using a SPME fiber assembly polydimethylsiloxane (PDMS) (1 cm long-100 $\mu \mathrm{m}$ thickness) from Supelco Ltd. Vials containing the samples were firstly conditioned for 30 minutes at $40{ }^{\circ} \mathrm{C}$ in a circulating water bath. After that, the fiber was exposed to the sample headspace during $30 \mathrm{~min}$ [31] and then desorbed for $1 \mathrm{~min}$ at $260{ }^{\circ} \mathrm{C}$ in the splitless mode in the gas chromatograph injector.

A Shimadzu GCMS-QP2010 gas chromatograph with mass detection up to 1024 mass/charge range was used with an SLB- $5 \mathrm{~ms}$ column $(30 \mathrm{~m} \times 0.25 \mathrm{~mm}$ i.d. $\times 0.25 \mu \mathrm{m}$ film thickness) from Sigma-Aldrich. Helium was used as carrier gas at a linear velocity of $30 \mathrm{~cm} / \mathrm{s}$.

The temperature of the interface and ion surface was 280 ${ }^{\circ} \mathrm{C}$ and $175^{\circ} \mathrm{C}$ respectively. The oven temperature was held at $35^{\circ} \mathrm{C}$ for 10 minutes, increased to $170^{\circ} \mathrm{C}$ at $2{ }^{\circ} \mathrm{C} / \mathrm{min}$ and then held at $170{ }^{\circ} \mathrm{C}$ for 5 minutes. Electron impact mass spectra were measured at $70 \mathrm{ev}$ ionization energy. The mass range varied from 29 to $700 \mathrm{amu}$. Identification of the constituents was based on computer matching against commercial NIST library mass spectra and literature data. Measurements were conducted in triplicate.

\subsection{Viscosity}

The viscosity of each sample was measured using a controlled stress AR 1000 (TA Instruments, UK) rheometer under low-amplitude oscillatory shear. A stainless still coneplate geometry (angle $1^{\circ}$, radius $20 \mathrm{~mm}$, gap $31 \mu \mathrm{m}$ ) was used. The olive oil was loaded into the rheometer previously thermostated at $40{ }^{\circ} \mathrm{C}$. Temperature was controlled by a Peltier system. A shear stress ramp ranging from 0 to $80 \mathrm{~Pa}$ was applied and the corresponding values of shear strain rate were recorded. Viscosity was obtained as the slope of the shear stress-shear strain rate. Three measurements of each olive oil sample were performed, and viscosity average value with its standard deviation was used in data analysis.

\subsection{Data Analysis}

Comparing the changes in the fingerprints provided by the sensors array and applying multivariate data analysis analyzed differences between samples. In the present work, we used the method of Principal component Analysis (PCA), an unsupervised statistic method that is useful for classification and data discrimination. This feature extraction method consists of projecting the $\mathrm{N}$-dimensional data set $(\mathrm{N}$ is the number of "sensors") in a new base of the same dimension $\mathrm{N}$, but now defined by the eigenvectors of the correlation matrix of the data set. The components of the original data vectors on this new base are the so-called principal components, obtaining one set of principal components $\left\{\mathrm{PC}_{1}, \ldots\right.$, $\left.\mathrm{PC}_{\mathrm{N}}\right\}$ for each data set $\left\{\mathrm{S}_{1}, \ldots, \mathrm{S}_{\mathrm{N}}\right\}$. The important point is that, when analyzing the new data set $\left\{\mathrm{PC}_{1}, \mathrm{PC}_{2}, \ldots, \mathrm{PC}_{\mathrm{N}}\right\}$, a large percentage of the total data variance is accumulated in a few of the principal components, representing a substantial reduction of the problem dimension and complexity. In those cases where an important percentage of the total data variance is contained in the first two or three principal components, the data points can be qualitatively discriminated by observing how they group in a score plot. PCA was performed for different cases, using different kind of sensors, that is: i) only gas sensors (data from the e-nose); ii) viscosity of the sample and gas sensors signals; iii) viscosity and gas chromatographic measurements. As magnitudes of the data measured were different according to the sensor used, PCA was made with the correlation matrix using a commercial software (S-PLUS 2000).

\section{RESULTS AND DISCUSSION}

\subsection{E-nose}

The radar plot of E-nose results for the sample EVOO 3 at different stages of the thermal treatment is shown in Fig. (1). Similar results were obtained for the other samples. There is an important increase in the intensity of the fingerprint when comparing the non-treated sample with the sample stored for 7 days at $90^{\circ} \mathrm{C}$. Besides, there is a change in the fingerprints pattern since not all the sensors increased their responses in the same proportion. This is due to the chemical changes that occur in the samples during the thermal treatment Indeed, not only the number but also the type of volatile compounds change with the temperature as a consequence of oxidative processes.

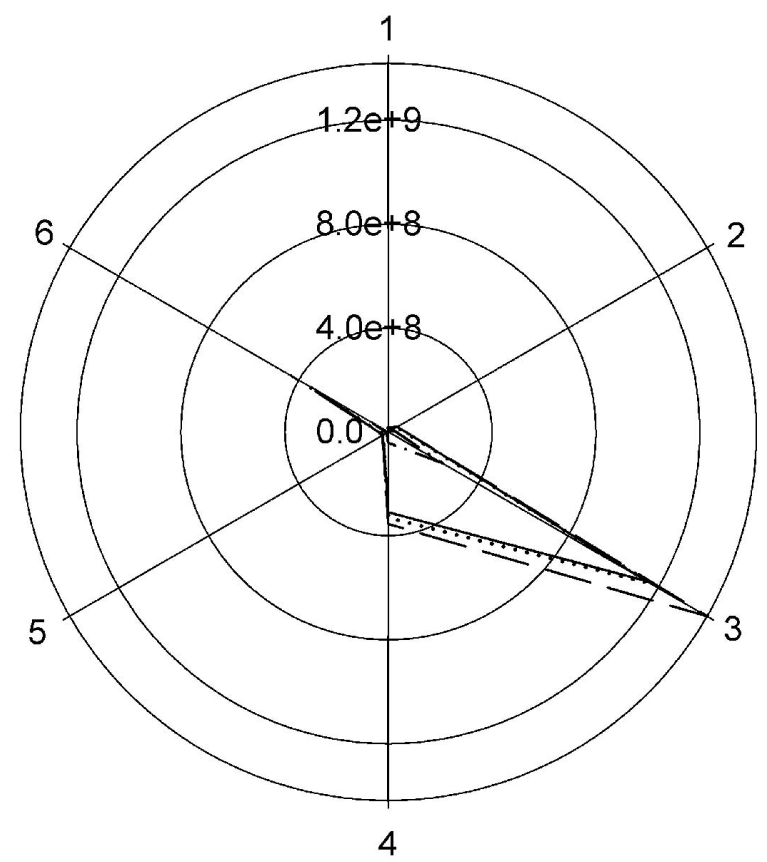

Fig. (1). Radar plots for sample EVOO 3 corresponding to the 4 different conditions evaluated: NT $(-\cdot)$ 7D (-), 14D ( …) and 28D ( - - ). Each vertex of the radar plot is the magnitude $\triangle \mathrm{R}$ in $\mathrm{Ohm}$ for each sensor. 
Table 2. Volatile Compounds Identified by Using SPME GC-MS in Olive Oil Samples Stored at $90^{\circ}$ for Different Times

\begin{tabular}{|c|c|c|c|c|c|}
\hline Retention Time(min) & Volatile Compound & \multicolumn{4}{|c|}{ Peak Area (\%) } \\
\hline 4.5 & 1-Penten-3-ol & $0.5 \mathrm{c}$ & $1.5 \mathrm{a}$ & $1.8 \mathrm{~b}$ & $2.0 \mathrm{c}$ \\
\hline 4.9 & Heptane & - & $6.7 \mathrm{~d}$ & $9.3 \mathrm{~d}$ & $10.7 \mathrm{a}$ \\
\hline 7.8 & 1-Pentanol & - & $1.2 \mathrm{e}$ & $1.4 \mathrm{~b}$ & $0.9 \mathrm{a}$ \\
\hline 8.7 & 3-Methyl 2-Butenal & - & $2.5 \mathrm{c}$ & $2.9 \mathrm{~b}$ & $2.3 b$ \\
\hline 9.0 & 1-Octene & - & $0.6 \mathrm{~b}$ & $0.2 \mathrm{c}$ & $0.5 \mathrm{a}$ \\
\hline 9.7 & Hexanal & $1.1 \mathrm{~b}$ & $12.0 \mathrm{~d}$ & $14.5 \mathrm{e}$ & $15.8 \mathrm{~b}$ \\
\hline 15.5 & 2-Hexen-1-ol & $0.5 \mathrm{~b}$ & $0.2 \mathrm{a}$ & - & - \\
\hline 16.0 & 1-Hexanol & $1.0 \mathrm{~d}$ & $0.6 \mathrm{a}$ & $0.3 \mathrm{a}$ & $0.2 \mathrm{a}$ \\
\hline 16.8 & Ethanone & - & $0.3 \mathrm{c}$ & $0.3^{\circ}$ & $0.2 \mathrm{a}$ \\
\hline 17.5 & 2-Heptanone & - & $0.8 \mathrm{a}$ & $0.9 \mathrm{~b}$ & $0.8 \mathrm{a}$ \\
\hline 17.8 & Pentanoic Acid & - & $0.1 b$ & $0.4 \mathrm{~b}$ & $0.4 \mathrm{~b}$ \\
\hline 18.4 & Heptanal & $0.7 \mathrm{~b}$ & $2.0 \mathrm{c}$ & $1.8 \mathrm{~b}$ & $1.2 \mathrm{c}$ \\
\hline 19.5 & 2-Hexen-1-ol Acetate & - & $0.3 b$ & $0.2 \mathrm{c}$ & $0.2 \mathrm{a}$ \\
\hline 26.5 & Hexanoic Acid & - & $1.0 \mathrm{~b}$ & $1.1 \mathrm{~d}$ & $0.8 \mathrm{~d}$ \\
\hline 27.4 & Octanal & $1.1 \mathrm{~b}$ & $2.5 \mathrm{~d}$ & $2.7 \mathrm{~d}$ & $2.2 \mathrm{c}$ \\
\hline 27.7 & 4-Hexen-1-ol Acetate & $0.5 \mathrm{~b}$ & $0.4 \mathrm{a}$ & $0.3 b$ & $0.2 \mathrm{~d}$ \\
\hline 28.1 & 2,4 Heptadienal & - & $1.4 \mathrm{a}$ & $1.5 \mathrm{~d}$ & $1.8 \mathrm{~b}$ \\
\hline 30.4 & 3-Octen-2-one & - & $0.5 b$ & $0.4 \mathrm{~b}$ & $0.3 \mathrm{a}$ \\
\hline 31.3 & 5-Ethyl diidro 2(3H)Furanone & - & $0.6 \mathrm{~b}$ & $0.5 \mathrm{a}$ & $0.4 \mathrm{a}$ \\
\hline 32.0 & 2-Octenal & - & $2.2 \mathrm{~b}$ & $2.6 \mathrm{~b}$ & $2.7 \mathrm{~b}$ \\
\hline 32.9 & 3,5 Octadien 2-one & - & $0.3 \mathrm{a}$ & $0.3 \mathrm{a}$ & - \\
\hline 33.2 & 1-Octanol & - & $1.2 \mathrm{~b}$ & $1.0 \mathrm{~b}$ & $0.7 \mathrm{a}$ \\
\hline 33.7 & Heptanoic Acid & - & $0.7 \mathrm{~b}$ & $0.5 \mathrm{a}$ & $0.5 \mathrm{a}$ \\
\hline 34.6 & 2-Nonanone & - & $0.3 \mathrm{a}$ & $0.5 b$ & $0.3 \mathrm{a}$ \\
\hline 35.7 & Nonanal & $2.5 \mathrm{e}$ & $8.3 \mathrm{c}$ & $6.3 \mathrm{c}$ & $5.0 \mathrm{c}$ \\
\hline 39.9 & 2-Nonenal & $0.4 \mathrm{~b}$ & $1.5 \mathrm{a}$ & $1.9 \mathrm{~b}$ & $2.1 \mathrm{~b}$ \\
\hline
\end{tabular}


Table 2. Contd.....

\begin{tabular}{|c|c|c|c|c|c|}
\hline Retention Time(min) & Volatile Compound & \multicolumn{4}{|c|}{ Peak Area (\%) } \\
\hline 41.3 & Octanoic Acid & - & $0.7 \mathrm{~d}$ & $1.5 \mathrm{~d}$ & $1.0 \mathrm{a}$ \\
\hline 43.4 & Decanal & $2.0 \mathrm{e}$ & $0.9 \mathrm{~b}$ & $1.1 \mathrm{c}$ & $0.9 \mathrm{a}$ \\
\hline 46.7 & 5 Butyl diidro 2(3H)Furanone & - & $0.4 \mathrm{~b}$ & $0.5 \mathrm{~b}$ & $0.4 \mathrm{~b}$ \\
\hline 47.4 & 2-Decenal & $1.0 \mathrm{c}$ & $6.7 \mathrm{e}$ & $8.9 \mathrm{e}$ & $9.7 \mathrm{~d}$ \\
\hline 47.8 & 3,7 Dimethyl 2,6 Octadienal & - & $0.8 \mathrm{a}$ & $0.7 \mathrm{~b}$ & $0.6 \mathrm{a}$ \\
\hline 48.2 & Nonanoic Acid & - & $1.4 \mathrm{c}$ & $2.1 \mathrm{~b}$ & $1.4 \mathrm{a}$ \\
\hline 54.3 & 2-Undecenal & $3.1 \mathrm{e}$ & $5.5 \mathrm{e}$ & $7.1 \mathrm{e}$ & $7.2 \mathrm{e}$ \\
\hline 54.9 & Copaene & $2.4 \mathrm{e}$ & $1.8 \mathrm{c}$ & - & - \\
\hline 57.2 & Dodecanal & $4.8 \mathrm{c}$ & $0.3 \mathrm{c}$ & - & - \\
\hline 59.6 & 6,10dimethyl 5,9Undecadien2-one $5.9 \mathrm{e}$ & $0.7 \mathrm{~d}$ & $0.3 \mathrm{a}$ & $0.4 \mathrm{~d}$ & \\
\hline 61.4 & 1-Dodecanol & $11.4 \mathrm{e}$ & $1.2 \mathrm{e}$ & - & - \\
\hline 62.7 & Alpha-Murolene & $5.1 \mathrm{e}$ & $0.5 \mathrm{~b}$ & $0.3 \mathrm{~b}$ & $0.2 \mathrm{a}$ \\
\hline 63.0 & Pentadecane & $11.0 \mathrm{e}$ & $0.9 \mathrm{~d}$ & - & $0.1 \mathrm{~b}$ \\
\hline
\end{tabular}

a RSD $<5 \%$; b $5<\mathrm{RSD}<15 \%$; c $15<\mathrm{RSD}<25 \%$; d $25<\mathrm{RSD}<50 \%$; e RSD $>50 \%$

\subsection{GC-MS}

The volatile compounds detected with GC-MS in the sample EVOO 3 at different stages of the thermal treatmentare listed in Table 2 together with the relative retention time and percentage contribution to the total area of the chromatogram. The overall effect of the thermal treatment was the increase of the total number of compounds. For a more useful data analysis [41] the compounds detected were grouped according to their functional groups: 1) aldehydes, 2) alcohols, 3) hydrocarbons, 4) ketones, 5) esters, 6) acids and 7) heterocyclic compounds. For each condition evaluated, the percentage contribution of each chemical family to the total chromatographic area was calculated and reported as a function of time, as shown in Fig. (2), for the case of sample EVOO 3. A large increase of the aldehydes was observed, as due to both the formation of new compounds and the increase of those already present in the fresh oil. This increase, responsible for off-flavors, is probably due to the breakdown of linoleic and linolenic fatty acids [42]. A large decrease in the relative amount of hydrocarbons was observed despite the notable formation of heptane. Even the total percentages of alcohols, ketones and esters decreased. The increase of heterocyclic compounds and acids, not present in the fresh oil, was also observed. It is known that the production of

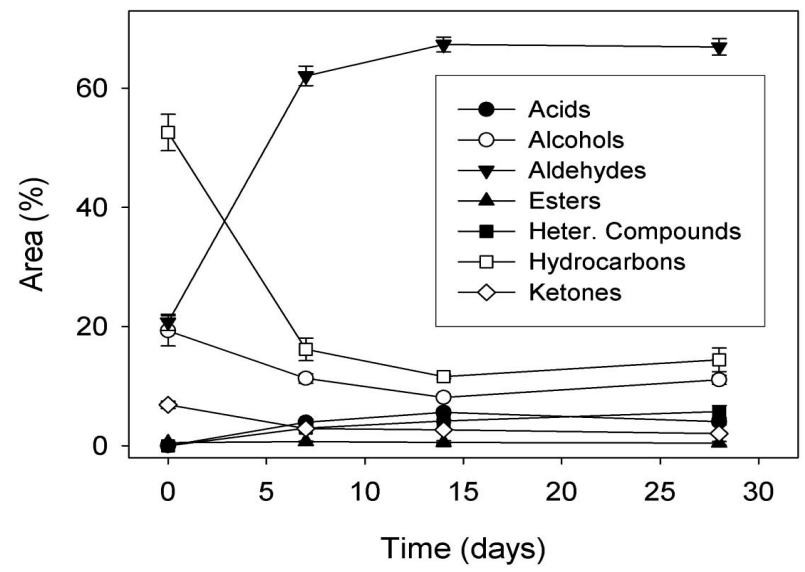

Fig. (2). Percentual contribution of each chemical family of compounds to the chromatographic area as a function of the time of storage at $90{ }^{\circ} \mathrm{C}$. 
aliphatic acid such as pentanoic, hexanoic, heptanoic, octanoic, or nonanoic acids indicative of thermal oxidation [27]. However, we noted that the main changes in composition were those between NT and 7D samples. Similar behaviors were observed for the other oils.

\subsection{Viscosity}

Fig. (3) shows the increase of viscosity with the duration of thermal treatment. This result is in quantitative agreement with those obtained by Santos, Santos and Souza (2005) [32], who observed a similar viscosity increase in olive oil kept at higher temperature $\left(190{ }^{\circ} \mathrm{C}\right)$ for shorter time $(8 \mathrm{hr}$.$) .$ At difference with the linear time dependence of viscosity observed by these authors, we noted an exponential rise toward a plateau.

\subsection{Data Analysis}

When analyzing all the samples within all the conditions tested, it was proved that the electronic nose was not sufficient to differentiate the samples. In fact, the addition of the viscosity as an extra variable to perform multivariate analysis improved the discrimination. But the best classification into groups according to the time of heat exposure was achieved when the relative amount of aldehydes, hydrocarbons and alcohols were also introduced as "sensors". These families of compounds were chosen as extra sensors to perform the PCA because they gave the highest variability among all the groups.

The PCA score plot is illustrated in Fig. (4), where each point corresponds to one measurement. More than $96 \%$ of the total data variance was contained in the score plot defined by $\mathrm{PC}_{1}$ and $\mathrm{PC}_{2}$, which yielded an effective dimension reduction in comparison with the total initial data set of ten variables. Two big groups were properly distinguished in the $\mathrm{PC}_{1}$ axis: the group of data with positive $\mathrm{PC}_{1}$ values, which corresponded to NT samples, and the group with negative $\mathrm{PC}_{1}$ values belonging to samples that were exposed to $90{ }^{\circ} \mathrm{C}$ for a certain period of time. Therefore, $\mathrm{PC}_{1}$ was able to char-

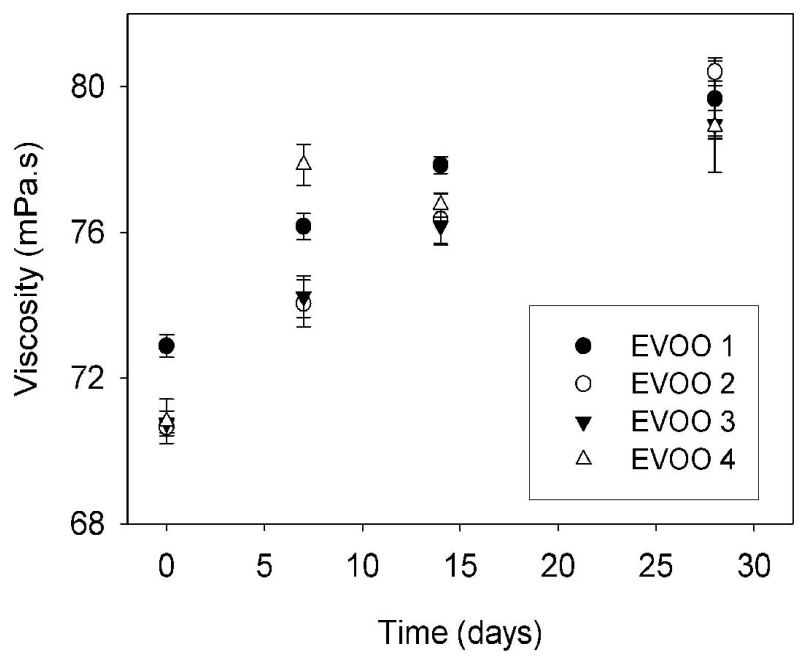

Fig. (3). Viscosity (mPa.s) as a function of the time of storage at 90 ${ }^{0} \mathrm{C}$ for the different EVOOs. Error bars indicate the standard deviation from 3 replicates. acterize the samples on the basis of their exposure to the thermal treatment. When analyzing data with negative $\mathrm{PC}_{1}$ values, three different groups were distinguished according to the duration of the thermal treatment. The first group, which presented positive values of $\mathrm{PC}_{2}$, belonged to samples treated for 7 days (triangles). The second group, which gave values of $\mathrm{PC}_{2}$ near zero, was assigned to samples that were treated for 14 days at $90^{\circ} \mathrm{C}$ (squares). The last group, which presented negative $\mathrm{PC}_{2}$ values, was identified as composed by the samples treated for 28 days (rhomboids). Thus, the change along the second principal component was in agreement with the storage time at $90{ }^{\circ} \mathrm{C}$. Cosio, Ballabio, Benedetti and Gigliotti (2007) [43] also related PC1 and PC2 responses with the different treatments of extra virgin olive oil.

Our results were achieved by mixing the responses of "sensors" based on different techniques. The only sample that belonged to the group of 7D and appeared at the group 14D was EVOO 4. When compared with the other samples, it also presented a distinctively higher viscosity, a more intensive fingerprint, and much larger content of oxidative compounds. This result confirms the idea that the increase of viscosity is correlated to the increase of intermolecular interactions between polar compounds produced by the exposure to a thermal treatment.

Since samples were well described by the PCA score plot, the loading plot (Fig. 5) was analyzed in order to show which "sensors" influenced most in the group discrimination. It can be inferred that sensors $1\left(\mathrm{SnO}_{2}-\mathrm{PT}\right)$ and $\left(\mathrm{In}_{2} \mathrm{O}_{3}+\mathrm{Ag}\right)$ from the e-nose, viscosity and both the relative amount of alcohols and hydrocarbons were the best sensors. A curious result was the correlation obtained between five e-nose sensors and the relative amount of aldehydes. The increase in the percentage of aldehydes in extra virgin olive oils with temperature occurred in a similar way for all the samples and the variability between them was not reflected by this variable. Probably, these sensors are highly sensitive to this

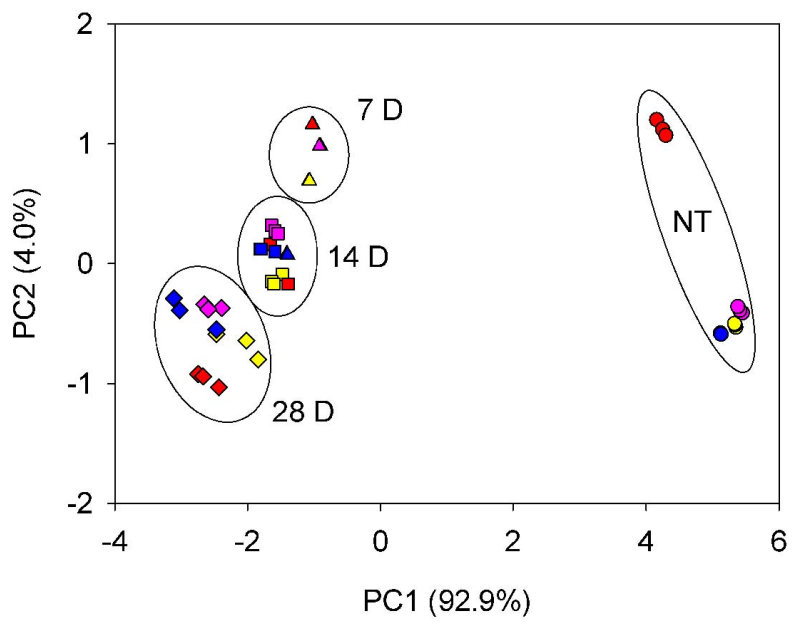

Fig. (4). PCA score plot for all the samples analyzed using e-nose sensors, viscosity and the relative amount of aldehydes, alcohols and hydrocarbons. Each sample corresponds to a measurement with this code: NT (circles), 7D (triangles), 14D (squares) and 28D (rhomboids). Color code: EVVO 1 = yellow; EVVO 2 = red; EVOO 3 = pink and EVVO $4=$ blue. 


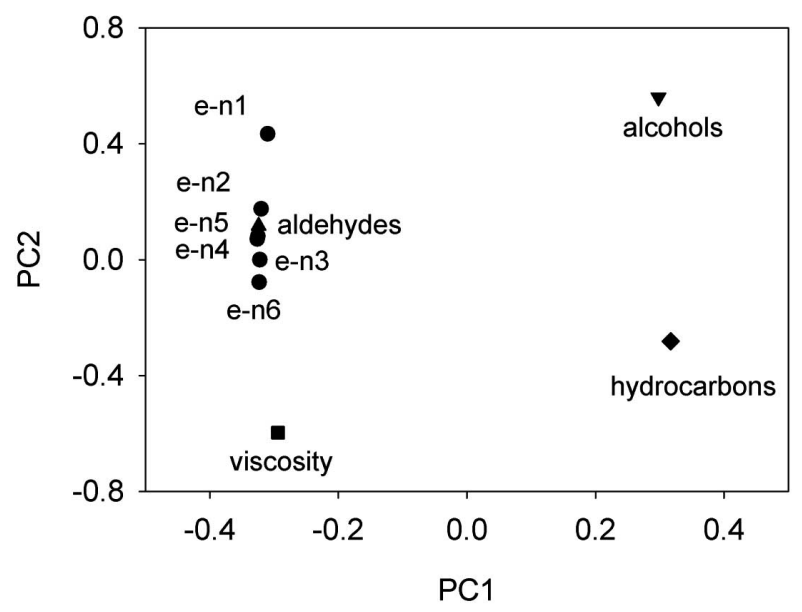

Fig. (5). Loading plot associated to the PCA shown in Fig. (4).

family of compounds. This plot evidences the importance of mixing these three techniques in order to improve the analysis.

Finally, Fig. (6) reports two different PCA score plots on data relative to fresh and 7 days treated samples, panels a) and b) respectively. Although relative to only four oils, the comparison shows that the thermal treatment causes a better discrimination between EVOO1 and EVOO4. This suggests that the joint use of a thermal treatment and a mixing of different techniques responses could be effective in discriminating between different oils.

\subsection{Concluding Remarks}

Sicilian extra virgin olive oil samples were stored at 90 ${ }^{0} \mathrm{C}$ and observed at different times. The thermal treatment produced a significant enhancement of e-nose fingerprints as well as an increase in the number and area of chromatographic peaks. This was due to the raise in number and concentration of the volatile compounds, mainly the polar fraction, in the samples headspace. The establishing of intermolecular interactions between the new formed polar compounds in the liquid phase was reflected into the viscosity increase.

Physical and chemical changes of samples caused by the thermal treatment were analyzed using Principal Component Analysis. All techniques' responses were mixed together in order to create a data matrix for the analysis. A synergistic effect was obtained by mixing different data, achieving an improvement in the discrimination of the oxidative stage. The comparison between the four different extra virgin olive oils suggested that the methodology could be also of help in discriminating within them according to their response to a thermal treatment.

\section{CONFLICT OF INTEREST}

The authors confirm that this article content has no conflicts of interest.
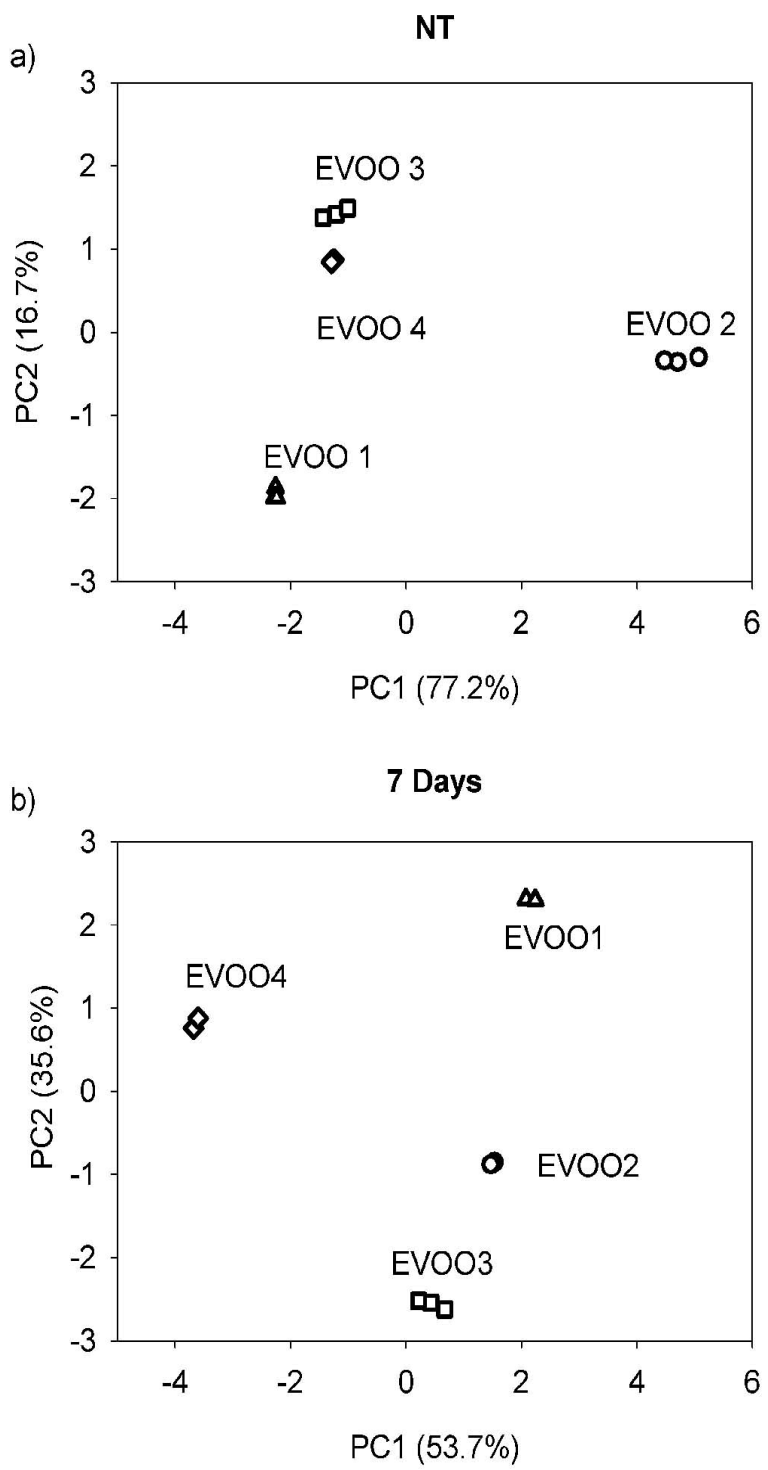

Fig. (6). PCA score plot for fresh oils samples (panel a) and after 7 days of thermal treatment (panel b), analyzed using e-nose sensors, viscosity and the relative amount of aldehydes, alcohols and hydrocarbons.

\section{ACKNOWLEDGEMENTS}

This work is part of a technological transfer project (P.O.R Sicilia 2000/2006-Misura 3.15-Sottoazione C) for quality control of Sicilian extra virgin olive oils. MEM had a postdoctoral fellowship from Consejo Nacional de Investigaciones Científicas y Técnicas (CONICET, Argentina).

The authors would like to thank Dr. V. Martorana for discussions and suggestions. Technical help from Mrs. F. Ferrante, F. Giambertone, G. Lapis, and M. Lapis is acknowledged.

\section{REFERENCES}

[1] Andrewes P, Busch JLHC, De Joode T, Groenewegen A, Alexandre H. Sensory properties of virgin olive oil phenols: Identification 
of deacetoxy-ligstroside aglycon as a key contributor to pungency. J Agric Food Chem 2003; 51: 1415-20.

[2] Gutierrez-Rosales F, Rios JJ, Gomez-Rey MAL. Main polyphenols in the bitter taste of virgin olive oil. Structural confirmation by on-line highperformance liquid chromatography electrospray ionization mass spectrometry. J Agric Food Chem 2003; 51: 6021-25.

[3] Hamdi KH, Castellon R. Oleuropein, a non-toxic olive iridoid, is an anti-tumor agent and cytoskeleton disruptor. Biochem Biophys Res Commun 2005; 334; 769-78.

[4] Beauchamp GK, Keast RSJ, Morel D, et al. Ibuprofen-like activity in extra-virgin olive oil. Nature 2005; 437: 45-6.

[5] Dugo G, La Pera L, Di Bella G. M. Sicilian virgin olive oils and red wines: a potentially rich sourse of antioxidant compound in the Mediterranean diet. Riv Ital Sostanze Grasse 2009; 86: 163-72.

[6] Bendini A, Cerretani L, Vecchi S, Carrasco-Pancorbo A, Lercker G. Protective effects of extra virgin olive oil phenolics on oxidative stability in the presence or absence of copper ions. J Agric Food Chem 2006; 54: 4880-7.

[7] Sinelli N, Cosio MS, Gigliotti C, Casiraghi E. Preliminary study on application of mid infrared spectroscopy for the evaluation of the virgin olive oil "freshness". Anal Chim Acta 2007; 598: 128-34.

[8] Brenes M, Garcìa, A, Dobarganes MC, Velasco J, Romero R. Influence of thermal treatments simulating cooking processeson the polyphenol content in virgin olive oil. J Agric Food Chem 2002; 50: 5962-7.

[9] Albi T, Lanzon A, Guinda A, Perez CMC, Leon M. Microwave and conventional heating effects on thermoxidative degradation of edible fats. J Agric Food Chem 1997; 45; 3795-8.

[10] Caponio F, Gomes T. Influence of olive crushing temperature on phenols in olive oils.Eur. Food Res Technol 2001; 212: 156-9.

[11] Allouche Y, Jiménez A, Gaforio JJ, Uceda M, Beltrán G. How heating affects extravirgin olive oil quality indexes and chemical composition. J Agric Food Chem 2007; 55: 9646-54.

[12] Kanavouras A, Hernandez RJ. The analysis of volatiles from thermally oxidized virgin olive oil using dynamic sorption-thermal desorption and solid phase micro-extraction techniques. Int J Food Sci Technol 2006; 41: 743-50.

[13] Sánchez-Gimeno AC, Negueruela AI, Benito M, Vercet A, Oria R. Some physical changes in Bajo Aragón extra virgin olive oil during the frying process. Food Chem 2008: 110: 654-8.

[14] Quiles JL, Ramírez-Tortosa MC, Gómez JA, Huertas JR, Mataix, J. Role of vitamin E and phenolic compounds in the antioxidant capacity, measured by ESR, of virgin oil, olive and sunflower oils after frying. Food Chem 2002; 76: 461-8.

[15] Valdés AF, Garcia AB. A study of the evolution of the physicochemical and structural characteristics of olive and sunflower oils after heating at frying temperatures. Food Chem 2006; 98: 214-9.

[16] Bastida S, Sánchez-Muniz FJ. Thermal oxidation of olive oil, sunflower oil and a mix of both oils during forty discontinuous domestic fryings of different foods. Food Sci Technol Int 2001; 7: $15-21$.

[17] Muik B, Lendl B, Molina-Díaz A, Ayora-Cañada MJ. Direct monitoring of lipid oxidation in edible oils by Fourier transform Raman spectroscopy. Chem Phys Lipids 2005; 134: 173-82.

[18] Bešter E, Butinar B, Bučar-Miklavčič M, Golob T. Chemical changes in extra virgin olive oils from Slovenian Istra after thermal treatment. Food Chem 2008; 108: 446-54.

[19] Carrasco-Pancorbo A, Cerretani L, Bendini A, Segura-Carretero A, Lercker G, Fernández-Gutiérrez A. Evaluation of the influence of thermal oxidation on the phenolic composition and on the antioxidant activity of extra-virgin olive oils. J Agric Food Chem 2007; 55: 4771-80.

[20] Guillen MD, Ruiz A. Study by means of ${ }^{1} \mathrm{H}$ nuclear magnetic resonance of the oxidation process undergone by edible oils of different natures submitted to microwave action. Food Chem 2006; 96: 665-74.

[21] Valavanidis A, Nisiotou C, Papageorgiou Y, et al. Comparison of the Radical Scavenging Potential of Polar and Lipidic Fractions of Olive Oil and Other Vegetable Oils under Normal Conditions and after Thermal Treatment. J Agric Food Chem 2004, 52, 2358-2365.
[22] Morales MT, Przybylski R. Olive Oil Oxidation. In Handbook of Olive Oil ; Harwood J, Aparicio R. Eds. Gaithersburg (MD): Aspen Publishers, 2000; pp. 459-90.

[23] Velasco J, Dobarganes C. Oxidative stability of virgin olive oil. Eur J Lipid Sci Technol 2002; 104: 661-76.

[24] Kalua CM, Allen MS, Bedgood DRJ, Bishop AG, Prenzler PD, Robards K. Olive oil volatile compounds, flavour development and quality: A critical review. Food Chem 2007; 100: 273-86.

[25] Benzie I. Lipid peroxidation: a review of causes, consequences, measurement and dietary influences. Int J Food Sci Nutr 1996; 47: 233-61.

[26] Angerosa F. Influence of volatile compounds on virgin olive oil quality evaluated by analytical approaches and sensor panels. Eur J Lipid Sci Tech 2002; 104: 639-60.

[27] Morales MT, Rios JJ, Aparicio R. Changes in the volatile composition of virgin olive oil during oxidation: flavors and off-flavors. J Agric Food Chem 1997; 45: 2666-73.

[28] EEC. Regulation (EC) 796/02. Charecterstic of olive and olive pomace oils and on their analytical methods: Off. J Eur Communities. Legis 2002; L128: 1-28.

[29] Davis BM, McEwan MJ. Determination of olive oil oxidative status by selected ion flow tube mass spectroscopy. J Agric Food Chem 2007; 55: 3334-8.

[30] Mildner-Szkudlarz S, Jelen HH. The potential of different techniques for volatile compounds analysis coupled with PCA for the detection of the adulteration of olive oil with hazelnut oil. Food Chem 2008; 110: 751-61.

[31] Vichi S, Castellote AI, PizzaleL, Conte LS, Buxaderas S, LópezTamames E. Analysis of virgin olive oil volatile compounds by headspace solid-phase microextraction coupled to gas chromatography with mass spectrometric and flame ionization detection. J Chromatogr A 2003; 983: 19-33.

[32] Santos JCO, Santos IMG, Souza AG. Effect of heating and cooling on rheological parameters of edible vegetable oils. J Food Eng 2005; 67: 401-5.

[33] Benedito J, Mulet A, Velasco J, Dobarganes MC. Ultrasonic assessment of oil quality during frying. J Agric Food Chem 2002; 50: 4531-6.

[34] Navarra G, Cannas M, D'Amico M, et al. Thermal oxidative process in extra virgin oils studied by FTIR, rheology and timeresolved luminescence. Food Chem 2011; 126: 1226-31.

[35] Apetrei C, Apetrei IM, Villanueva S, De Saja JA, GutierrezRosales F, Rodriguez-Mendez ML. Combination of an e-nose, an e-tongue and an e-eye for the characterisation of olive oils with different degree of bitterness. Anal Chim Acta 2010; 663: 91-7.

[36] Casale M, Casolino C, Oliveri P, Forina M. The potential of coupling information using three analytical techniques for identifying the geographical origin of Liguria extra virgin olive oil. Food Chem 2010, 118: 163-70.

[37] Lerma-Garcia MJ, Simo-Alfonso EF, Bendini A, Cerretani L. Metal oxide semiconductor sensors for monitoring of oxidative status evolution and sensory analysis of virgin olive oils with different phenolic content. Food Chem 2009; 117: 608-14.

[38] Garcia-Gonzales DL, aparicio R. Coupling MOS sensors and gas chromatography to interpret the sensor responses to complex food aroma: application to virgin olive oil. Food Chem 2010; 120: 5729.

[39] EEC. Regulation 2568/91. Characteristics of olive and olivepomace oil and on their analytical methods. Off J Eur Commun Legis 1991: L248, 1-82.

[40] Falasconi M, Pardo M, Sberveglieri G, Riccò I, Bresciani A. The novel $\operatorname{EOS}^{385}$ electronic nose and data analysis for evaluating coffee ripening. Sens Actuators B 2005; 110: 73-80.

[41] Manai H, Mahjoub-Haddada F, Oueslati I, Daoud D, Zarrouk M. Characterization of monovarietal virgin olive oils from six crossing varieties. Sci Hortic 2008; 115: 252-60.

[42] Cavalli JF, Fernandez X, Lizzani-Cuvelier L, Loiseau AM. Characterization of volatile compounds of French and Spanish virgin olive oils by HS-SPME: Identification of quality-freshness markers. Food Chem 2004; 88: 151-7. 
[43] Cosio MS, Ballabio D, Benedetti S, Gigliotti C. Evaluation of different storage conditions of extra virgin olive oils with an inno- vative recognition tool built by means of electronic nose and electronic tongue. Food Chem 2007; 101: 485-91.

(C) Amenta et al.; Licensee Bentham Open.

This is an open access article licensed under the terms of the Creative Commons Attribution Non-Commercial License (http://creativecommons.org/licenses/by-nc/3.0/) which permits unrestricted, non-commercial use, distribution and reproduction in any medium, provided the work is properly cited. 